\title{
Essential Oils Applied on Sticky Traps Increase Trapping of Sucking Pests under Greenhouse Condition
}

\author{
${ }^{1}$ Negasu Guteta Bayisa, ${ }^{2}$ Nigusie Hundesa, ${ }^{3}$ Banchiamlak Nigussie Tefera \\ ${ }^{123}$ Ethiopia Institute of Agricultural Research, Wondo Genet Center, Shashemene, Ethiopia
}

\begin{abstract}
Thrips (Thripsspp), whitefly (Bemisiaspp) and leaf miners (Liriomyzaspp) are among the major serious pests of herbs growing in Hawassa Greenhouse Mark. Development of alternative management methods for agriculturally important insect pests is needed due to the adverse effect of pesticides to human health and the environment. The objective of the present study is to evaluate the effectiveness of natural essential oils added to sticky traps to increasing the trapping efficiency of the sticky traps to manage leaf miner, thrips and whitefly on green basil (Ocimumbasilicum L.), chives (Allium schoenoprasumL.) and tarragon(Artemisia dracunculus) in green houses. The experiment was conducted concurrently for green basil, chives and tarragon grown in the greenhouses in an area of 0.67 ha wide. Nine sticky traps and six natural essential oils were used in four cycles within two months interval and replicated three times, arranged in randomize complete block design. Variation in each treatment was analyzed using ANOVA and LSD at P<0.05was used to separate the means. The results showed that yellow sticky traps that were coated with the essential oils were more effective in attracting the three pests than uncoated sticky traps in greenhouse. Higher number leaf miners were attracted by sticky traps coated with lavender oil, lemon oil and castor oil. Higher number of whiteflies and thrips were attracted bylavender oil and basil oil coated yellow sticky traps, respectively. Therefore, using yellow sticky traps with natural essential oils reduced the pest population and also contributed in the management. The approach produced useful information for integrated pest management strategy and also to determine the threshold level for control options to be employed. Thus information generated will be useful to help growers in making management decisions against the underlying insect pests on green basil, chives and tarragon at Hawassa greenhouse mark herbs.
\end{abstract}

Keywords: Essential oil, sticky traps, leaf miners, thrips, whitefly, green basil, chives and tarragon.

\section{INTRODUCTION}

Chives (Allium schoenoprasumL.), green basil (Ocimumbasilicum L), and tarragon (Artemisia dracunculus), are major herbs produced in Hawassa Green Mark Herbs Plc in Ethiopia for export purpose. Thrips (Thripsspp), whitefly (Bemisiaspp) and leaf miners (Liriomyzaspp) are among the major serious pest in the greenhouses. They cause leaf distortion, yellowing, stunted grow thin the herbs and vegetable crops cultivated in the greenhouses. The warm, humid conditions and abundant food in a greenhouse provides an excellent, stable environment for pest development. Often, the natural enemies that serve to keep pests under control outside may not be present in the greenhouse at a population density enough to control the pests. For these reasons, pest situations often develop in this indoor environment more rapidly and with greater severity than at outdoors (RicBessin et al., 1997).

Minimum use of pesticides is desired in pest control to cope with various problems associated with the over-use of pesticides :acute toxicity to humans and animals, pest resistance to pesticides, pest resurgence, emergence of new pests, high cost of control practices, pesticide residue problems (Miller,2004). In order to achieve maximal effects of pest control with minimum application of pesticides accurate estimation of pest densities in field condition is basic. Besides minimal use of pesticides, development of alternative methods for the management of agriculturally important insect pests is needed to be cost effective and eco-friendly. Sticky traps have been widely used to monitor flying insects in many agro-ecosystems especially for monitoring purpose including whitefly, thrips and leaf miners and are the most preferable method for the management of some insects in greenhouses. These traps are widely used for monitoring and management of whiteflies, aphids, leaf miners, thrips, leafhoppers and certain other insect pests (Liburd etal., 1998; Kim et al., 1999; Kumawat et al., 2000; Doukas, 2002; Fiedler and Sosnowska, 2002). 
These days, essential oils are better than insecticides to use them for the control of insect pests because they help to keep the environment safe and avoid health hazards from intense insecticide use. The observed increased response of insects to definite colors inspired entomologists in the past to apply colored sticky traps in insect pest control. In addition to yellow sticky traps, the evaluation of efficacy of natural essential oils odour as attractants to insect pests has been found to be effective to control key pests (Premalatha and Rajangam, 2011). So it is important to study of the effectiveness of different essential oils as possible attractants of insect pest in green house when combined with colored sticky traps. Therefore, the main objective of the present study is to evaluate the effectiveness of natural essential oils added to sticky traps to increasing the trapping efficiency of the sticky traps to manage leaf miners, thrips and white flies on green basil, chives and tarragon in green houses at Hawassa Green Mark Herbs Plc, Ethiopia.

\section{MATERIALS AND METHODS}

\subsection{Site Description}

The experiment was carried out in the greenhouse of Green Mark Herbs PLC, Ethiopia at Hawassa from November to April in 2015. It is located at $7^{0} 05^{\prime} \mathrm{N}$ latitude and $39^{0} 29^{\prime} \mathrm{E}$ longitude. Soil $\mathrm{PH}$ is 7.2 with sandy loam soil type (Andosol). The elevation is $1652 \mathrm{~m}$ a.s.l. with total annual rainfall of 964 $\mathrm{mm}$ and monthly maximum and minimum temperatures of $12.94{ }^{\circ} \mathrm{C}$ and $27.34{ }^{\circ} \mathrm{C}$, respectively.

Trapping studies were conducted concurrently for green basil, chives and tarragon growing in the greenhouses that were 0.67 hawideeach. Nine treatments were designed for each experiment. Before treatments application those pests (thrips, leaf miners and whiteflies infestation) were assessed and confirmed whether the target crops were highly infested in the greenhouse. Oils of rosemary (Rosemarinus officinalis L.), geranium (Pelargonium graveolensL.), basil (OcimumbasilicumL.), lemon grass (CymbopogoncitratusL.), lavender (LavandulaangustifoliaL.) and castor (Ricinus communis L.) were included in the experiment. The essential oils were obtained from Wondo Genet Agriculture Research Center, Natural products Laboratory. In the control combinations, three controls (colorless, blue and yellow sticky traps) were used without addition of natural essential oil.

The sticky traps were made from paper $(21 \times 15 \mathrm{~cm})$ and were sealed with a thin transparent plastic cover, and smeared with sticky glue. Subsequently, essential oil was painted sticky traps in the amount of $0.1 \mathrm{ml}$ on both sides accordingly. Nine sticky traps were used in each experiment, done in four cycles within two month interval and replicated three times by using complete randomize design. During the experiments, the traps were hung about $30 \mathrm{~cm}$ above the crop canopies, equally distributed in the green house and could be adjusted vertically whenever the crop attained additional growth.

Sticky traps were randomly and uniformly hung in the greenhouse in three selected greenhouses (about 27 traps in one greenhouse).During the trials no insecticides were applied in greenhouses. After seven days from the moment of suspension, the traps were removed from suspensions and the numbers of leaf miners, whiteflies and thrips adults captured were counted per each sticky trap.

In the first experimental series for green basil plant via yellow sticky traps coated with geranium oil, yellow sticky traps coated with lavender oil, blue sticky traps coated with geranium oil, blue sticky traps coated with lavender oil, colorless sticky traps coated with geranium oil, colorless sticky traps coated with lavender oil, yellow sticky traps, blue sticky traps and colorless sticky traps were used to tested for the control of leaf miners and whiteflies.

In the second experimental series for chives plant via yellow sticky traps coated with rosemary oil, yellow sticky traps coated with lemon oil, blue sticky traps coated with rosemary oil, blue sticky traps coated with lemon oil, colorless sticky traps coated with rosemary oil, colorless sticky traps coated with lemon oil, yellow sticky traps, blue sticky traps and colorless sticky traps were used to tested for the control of thrips and leaf miners.

In the third experimental series for tarragon plants via yellow sticky traps coated with geranium oil, yellow sticky traps coated with lavender oil, blue sticky traps coated with geranium oil, blue sticky traps coated with lavender oil, colorless sticky traps coated with geranium oil, colorless sticky traps coated with lavender oil, yellow sticky traps, blue sticky traps and colorless sticky traps were used tested for the control of leaf miners and whiteflies.

The obtained results were statistically analyzed by analysis of variance (ANOVA) using (SAS Version 9.0) PROC GLM (2002) at $\mathrm{P}<0.05$. Differences between means were assessed using the least significance difference (LSD) test at $\mathrm{P}<0.05$. 


\section{RESULTS AND DISCUSSIONS}

\subsection{Trap Success of Leaf Miner and Whitefly in green Basil}

\section{Leaf Miners}

The combined mean of leaf miners and whiteflies captured per each sticky trap are presented in table 1.The data showed that there were statistically significant differences $(\mathrm{P}<0.05)$ among the treatments of yellow sticky traps coated with lavender oil, colorless sticky traps coated with lavender oil, blue sticky traps and colorless sticky traps. However, there were no statistically significant $(\mathrm{P}<0.05)$ differences among yellow sticky traps coated with geranium oil, blue sticky traps coated with geranium oil, blue sticky traps coated with lavender oil, colorless sticky traps coated with geranium oil and yellow sticky traps. The highest mean number of leaf miners adults captured per yellow sticky traps coated with lavender oil was 34.92 followed by colorless sticky traps coated with the same oil (24.83). The lowest mean number was recorded on colorless sticky traps (13.58). In general, the treatments/traps that coated with lavender oil caught more number of leaf miners adults. Regardless of the color effect, lavender oil coated on colorless sticky traps caught more number of leaf miners adults (24.83) than yellow sticky traps that is not coated with any other essential oil (18.17).

\section{Whiteflies}

Highest number whiteflies adults were captured per yellow sticky traps coated with lavender oil (795.92) followed by yellow sticky traps (704.75) and yellow sticky traps coated with geranium oil (544.92) (Table 1). The same trend also observed among the colorless sticky traps that colorless sticky traps coated with lavender oil caught higher number of whiteflies adults even if the numbers of whiteflies attract towards colorless sticky traps lower than yellow and blue sticky traps. Thus, lavender oil is effective in attracting whiteflies. Therefore, a yellow sticky trap coated with lavender oil was more effective to catch whiteflies and can used to monitor and reduce whiteflies population on green basil. Other findings indicated that irrespective of the varieties, yellow chart coated with castor oil attracted higher number of whiteflies than yellow sticky trap (Premalatha and Rajangam, 2011). According to Lu et al., 2012, yellow sticky traps can be used to monitor and control whiteflies in the greenhouse but, yellow sticky traps can be used as a monitoring only in the field. Kim et al. (1999) reported the numbers of whiteflies on yellow sticky traps were significantly correlated to plants. However, Soto et al. (2001) mentioned that the abundance and population dynamics of whiteflies varied depending on whiteflies species, area and crops.

Table 1. Mean number of leaf miners and whiteflies captured per sticky traps treatments conducted from green basil plant in the greenhouse.

\begin{tabular}{|l|l|l|l|}
\hline S/N & Treatment & Leaf miner & Whitefly \\
\hline 1 & Yellow sticky traps coated with geranium oil & $21.17^{\text {cb }}$ & $544.92^{\mathrm{c}}$ \\
\hline 2 & Yellow sticky traps coated with lavender oil & $34.92^{\mathrm{a}}$ & $795.92^{\mathrm{a}}$ \\
\hline 3 & Yellow sticky traps & $18.17^{\text {ced }}$ & $704.75^{\mathrm{b}}$ \\
\hline 4 & Blue sticky traps coated with geranium oil & $15.92^{\text {ed }}$ & $296.42^{\text {edf }}$ \\
\hline 5 & Blue sticky traps coated with lavender oil & $20.58^{\text {cbd }}$ & $327.08^{\mathrm{d}}$ \\
\hline 6 & Blue sticky traps & $18.83^{\text {cd }}$ & $322.42^{\text {ed }}$ \\
\hline 7 & Colorless sticky traps coated with geranium oil & $22.25^{\text {cd }}$ & $228^{\mathrm{f}}$ \\
\hline 8 & Colorless sticky traps coated with lavender oil & $24.83^{\mathrm{b}}$ & $241.17^{\text {ef }}$ \\
\hline 9 & Colorless sticky traps & $13.58^{\mathrm{e}}$ & $131.17^{\mathrm{g}}$ \\
\hline Mean & & 21.14 & 399.09 \\
\hline CV & 28.52 & 25.97 \\
\hline
\end{tabular}

Means followed by the same letters with in the same column are not statistically significant at $\mathrm{p}<0.05$ according to the least significant difference (LSD) test.

\subsection{Trap Success of Leaf Miners and Thrips in chives Grown in Greenhouse}

\section{Leaf Miners}

The results showed that the highest number of leaf miners captured by yellow sticky traps followed by blue sticky traps. There was statistically significant difference $(\mathrm{P}<0.05)$ among the treatments. Yellow sticky traps had the number of leaf miners catch of 233.7. This trap coated with lemon oil was the highest $(303.83)$. There was no significant difference $(\mathrm{P}<0.05)$ between blue sticky traps and coated with of rosemary and lemon oils. This might be due to color effect that the leaf miners were not attracted to blue sticky traps. Even if the number leaf miners captured by colorless sticky trap was the lowest one, there was statistically significant difference among the treatments. In general, yellow 
sticky traps coated with lemon oil captured highest number leaf miners and it is the ideals for control of leaf miners from chives plant in the greenhouse. Milligan et al., (1988) indicated that monitoring population is useful to detect insect problems in crops and to determine whether control measures have been effective.

Thrips

The data showed that highest numbers of thrips were captured by yellow sticky traps followed by blue sticky traps and colorless sticky traps (table 2).The highest number of thrips was captured on yellow sticky traps (377.8) followed by yellow sticky trap coated with rosemary oil (325.6) while the lowest was on colorless sticky traps coated with rosemary oil (61.2).

Table 2. Mean number of leaf miners and thrips captured per sticky traps treatments conducted from chives plant in the greenhouse.

\begin{tabular}{|l|l|l|l|}
\hline S/N & Treatments & Leaf miner & Thrips \\
\hline 1 & Yellow sticky traps coated with rosemary oil & $146.17^{\text {ced }}$ & $325.58^{\text {ba }}$ \\
\hline 2 & Yellow sticky traps coated with lemon oil & $303.83^{\text {a }}$ & $223.83^{\text {c }}$ \\
\hline 3 & Yellow sticky traps & $233.75^{\text {b }}$ & $377.75^{\text {a }}$ \\
\hline 4 & Blue sticky traps coated with rosemary oil & $191.42^{\text {cbd }}$ & $130.17^{\text {d }}$ \\
\hline 5 & Blue sticky traps coated with lemon oil & $152.08^{\text {ced }}$ & $93.58^{\text {ed }}$ \\
\hline 6 & Blue sticky traps & $130^{\text {fed }}$ & $267.67^{\text {bc }}$ \\
\hline 7 & Colorless sticky traps coated with rosemary oil & $207.33^{\text {cb }}$ & $61.17^{\mathrm{f}}$ \\
\hline 8 & Colorless sticky traps coated with lemon oil & $72.25^{\mathrm{f}}$ & $166.08^{\text {ed }}$ \\
\hline 9 & Colorless sticky traps & $95.67^{\text {fe }}$ & $99.67^{\text {de }}$ \\
\hline Mean & & 170.28 & 188.38 \\
\hline CV & & 44.64 & 42.09 \\
\hline
\end{tabular}

Means followed by the same letters with in the same column are not statistically significant at $\mathrm{p}<0.05$ according to the least significant difference (LSD) test.

\subsection{Trap Success of Leaf Miners and Thrips from Tarragon in Greenhouse}

\section{Leaf Miners}

The result showed that the highest numbers of leaf miners were captured per yellow sticky traps followed by blue sticky traps and color less sticky traps. Yellow sticky traps captured the highest number of leaf miners (72.92) followed by yellow sticky traps coated with castor oil (66.25) and the differences were statistically significant $(\mathrm{P}<0.05)$ between the treatments(Table 3$)$. Yellow, blue and colorless sticky traps coated with castor oil relatively showed that it was captured high number leaf miners.

\section{Thrips}

The result summarized in table 3 and the treatments showed that statistically significant difference among the treatments $(\mathrm{P}<0.05)$. The highest numbers of thrips were caught on yellow sticky traps coated with basil oil followed by yellow sticky traps. In general, within the different color of sticky traps, the highest numbers trips were captured by sticky traps coated by basil oil. Therefore, yellow sticky traps coated with basil oil can be used for controlling the insect along with other management practices under greenhouse conditions. The populations of thrips adults were greater than leaf miners. Those traps provided a measure of the relative abundance of thrips and a highly significant relationship was reported between the number of trapped insect and the trap size (Cho et al., 1998; Kim et al., 1999, Tomkin Is, 2002; Carrizo and Benitez, 2002).

Table 3. Mean number of leaf miners and thrips captured per sticky traps treatments conducted from tarragon plant in the greenhouse.

\begin{tabular}{|l|l|l|l|}
\hline S/N & Treatment & Leaf miners & Thrips \\
\hline 1 & Yellow sticky traps coated with basil oil & $50.25^{\mathrm{b}}$ & $841.58^{\mathrm{a}}$ \\
\hline 2 & Yellow sticky traps coated with castor oil & $66.25_{\mathrm{a}}$ & $525.67^{\mathrm{c}}$ \\
\hline 3 & Yellow sticky traps & $72.92^{\mathrm{a}}$ & $704^{\mathrm{b}}$ \\
\hline 4 & Blue sticky traps coated with basil oil & $23.17^{\mathrm{dc}}$ & $310.33^{\mathrm{d}}$ \\
\hline 5 & Blue sticky traps coated with castor oil & $33.83^{\mathrm{c}}$ & $200.25^{\text {ed }}$ \\
\hline 6 & Blue sticky traps & $21.42^{\mathrm{dc}}$ & $305.92^{\mathrm{d}}$ \\
\hline 7 & Colorless sticky traps coated with basil oil & $20.75^{\mathrm{d}}$ & $178.08^{\mathrm{e}}$ \\
\hline 8 & Colorless sticky traps coated with castor oil & $24.5^{\mathrm{dc}}$ & $119.08^{\mathrm{e}}$ \\
\hline 9 & Colorless sticky traps & $20.92^{\mathrm{d}}$ & $151.75^{\mathrm{e}}$ \\
\hline
\end{tabular}




\begin{tabular}{|l|l|l|}
\hline Mean & 37.11 & 370.74 \\
\hline CV & 42.18 & 41.66 \\
\hline
\end{tabular}

Means followed by the same letters with in the same column are not statistically significant at $\mathrm{p}<0.05$ according to the least significant difference (LSD) test.

\section{CONCLUSION}

The results showed yellow sticky traps that coated with essential oils were effective to attract insect pests in the greenhouse. Higher number of leaf miner was attracted to wards sticky traps that coated with lavender oil, lemon oil and castor oil. Higher number of whiteflies and thrips attracted towards lavender oil and basil oil, respectively. Therefore, using yellow sticky traps with natural essential oils can be used to monitor, pest population reduction, as part of integrated pest management strategy and also help to determine the threshold level for action.

\section{ACKNOWLEDGEMENTS}

The authors are grateful to the Wondo Genet Agriculture Research Center for providing all the necessary facilities and support during the entire experiment. Our special thanks also go to Yonas Belachew for his helps in greenhouse activities and data collection.

\section{REFERENCES}

[1] Cho KiJong; Kang SangHoon and Lee JeangOon (1998).Spatial distribution of thrips in greenhouse cucumber and development of a fixed - precision sampling plan for estimating population density. Journal of Asia Pacific Entomology, 1 (2): 163-170.

[2] Carrizo, P. and D. Benitez. (2002). Frankliniellaoccidentalis (Pergande): caught on yellow sticky traps. Revista de la Facultad de Ciencias Agrarias, Universidad Nacional de Cuyo, 34 (2): 87-91.

[3] Doukas, D. 2002. Impact of spectral cladding materials on the behavior of glasshouse whitefly Trialeurodesvaporariorum and Encarsiaformosa, its hymenopteran parasitoid. The BCPC conference: Pests and diseases, Vol. (1 and 2), pp. 773-776.

[4] Fiedler, Z. and D. Sosnowska .2002.Coloured sticky traps for monitoring the pests of ornamental plants in the palm House in Poznan. Progress in Plant Protection, 42 (2): 424-426.

[5] G. T. Miller, Sustaining the Earth, Thompson Learning, Inc., Pacifice Grove, California, 2004, pp. 211-216.

[6] Liburd, O. E.; S. R. Alm; R. A. Casagrande and S. Polavarapu. (1998) Effect of trap color, bait, shape and orientation in attraction of blueberry maggot flies (Diptera: Tephritidae). Journal of Economic Entomology, 91(1): 243-249.

[7] Lu Y, Bei Y, Zhang J. 2012. Are Yellow Sticky Traps an Effective Method for Control of Sweet potato Whitefly, Bemisiatabaci, in the Greenhouse or Field? Journal of Insect Science; 12:113. doi:10.1673/031.012.11301.

[8] Kim JongKwan; Park JungJoon; Pak ChunHo; Park HeungSun and Cho KiJong (1999).Implementation of yellow sticky trap for management of greenhouse whitefly in cherry tomato greenhouse. Journal of the Korean Society for Horticultural Science, 40 (5): 549-553.

[9] Kumawat, R. L.; B. L. Pareek and B. L. Meena .2000.Seasonal incidence of jassid and whitefly on okra and their correlation with abiotic factors. Annals of Biology, 16 (2): 167-169.

[10] Milligan, R. H.; G. O. Osborne and G. Ytsma (1988).Evidence for an aggregation pheromone in Platypus gracilisBroun (Col., Platypodidae). Journal of Applied Entomology, 106 (1): 20-24.

[11] Premalatha K. and Rajangam, K. P. (2011). Efficacy of yellow sticky traps against greenhouse whitefly,Trialeurodes vaporariorum (Westwood) (Aleyrodidae: Hemiptera) in gerbera. Journal of Biopesticides , 208-210.

[12] RicBessin, Lee H. Townsend and Robert G. Anderson (1997).Greenhouse Insect Management. Frankfort: University of Kentucky College of Agriculture, Lexington, and Kentucky State University.

[13] Soto, A.; F. Ohlenschlager and F. Garcia-Mari (2001). Population dynamics and biological control of the whiteflies Aleurothrixusfloccosus, Dialeurodescitri and Parabemisiamyricae (Homoptera: Aleyrodidae) in citrus orchards of Valencia (Spain). Boletin de Sanidad Vegetal, Plagas, 27 (1): 3-20.

[14] Tomkins, A. R. (2002). Monitoring thrips with sticky traps. Grower, 57 (11): 20-22. 